\title{
Effect of age and vaccination on extent and spread of Chlamydia pneumoniae infection in C57BL/6 mice
}

\author{
Taylor Eddens', Sarah Beaudoin², Amanda Steinberger ${ }^{2}$, C Scott Little ${ }^{2}$, Dawn Shell², Benjamin Wizel ${ }^{3,5}$, \\ Brian Balin ${ }^{2}$ and Kerin L Fresa-Dillon ${ }^{4^{*}}$
}

\begin{abstract}
Background: Chlamydia pneumoniae is an obligate intracellular respiratory pathogen for humans. Infection by $C$. pneumoniae may be linked etiologically to extra-respiratory diseases of aging, especially atherosclerosis. We have previously shown that age promotes C. pneumoniae respiratory infection and extra-respiratory spread in BALB/C mice.

Findings: Aged C57BL/6 mice had a greater propensity to develop chronic and/or progressive respiratory infections following experimental intranasal infection by Chlamydia pneumoniae when compared to young counterparts. A heptavalent CTL epitope minigene (CpnCTL7) vaccine conferred equal protection in the lungs of both aged and young mice. This vaccine was partially effective in protecting against C. pneumoniae spread to the cardiovascular system of young mice, but failed to provide cardiovascular protection in aged animals.

Conclusions: Our findings suggest that vaccine strategies that target the generation of a C. pneumoniae-specific $C T L$ response can protect the respiratory system of both young and aged animals, but may not be adequate to prevent dissemination of C. pneumoniae to the cardiovascular system or control replication in those tissues in aged animals.
\end{abstract}

Keywords: Chlamydia pneumoniae, Aging, Vaccine

\section{Rationale and hypothesis}

Chlamydia pneumoniae is an important respiratory pathogen in humans [1]. Extra-respiratory spread may be common and with consequence: C. pneumoniae or chlamydial DNA has been detected in the coronary arteries of $46 \%$ of individuals with atherosclerosis, but rarely in individuals without coronary artery disease [2]. C. pneumoniae-specific $\mathrm{T}$ cells have also been detected within atheromatous plaques [3].

Infection by $C$. pneumoniae is common in western countries, at least $70 \%$ of the total population has been infected by age $65[4,5]$. Pneumonia poses a high risk of morbidity and mortality in aged humans, and vaccines against respiratory pathogens are often less effective in

\footnotetext{
*Correspondence: kerinf@pcom.edu

${ }^{4}$ Department of Pathology, Microbiology, and Immunology, the Philadelphia College of Osteopathic Medicine, 4170 City Avenue, Philadelphia, PA 19131, USA

Full list of author information is available at the end of the article
}

the elderly [reviewed in [6]]. Thus, there is a need for vaccine strategies that prevent both respiratory infection and extra-respiratory spread of C. pneumoniae in aged, as well as young individuals.

We have previously established in BALB/c mice that aging was associated with impaired resolution of respiratory C. pneumoniae infection, more extensive inflammation and consolidation within the infected lung, enhanced spread of C. pneumoniae to the cardiovascular system and increased inflammation within the heart [7]. We sought to extend these findings to a genetically disparate strain, $\mathrm{C} 57 \mathrm{BL} / 6$, which has been shown to mount a strong Th1-polarized immune response specific for C. pneumoniae [8,9]. We also hypothesized that a heptavalent cytotoxic T cell (CTL) epitope DNA minigene vaccine (CpnCTL7) [10], which has been shown to generate epitope-specific $\mathrm{CD} 8^{+} \mathrm{CTL}$ capable of IFN- $\gamma$ and TNF- $\alpha$ secretion and cytolytic activity against $C$.

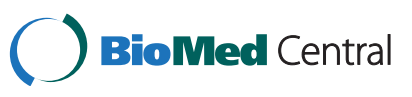


pneumoniae infected macrophages in vitro. and reduce mean respiratory bacterial titers in young, C. pneumoniae-infected C57BL/6 mice [10], would be less effective in prevention of respiratory and cardiovascular C. pneumoniae infection in aged C57BL/6 mice.

\section{Methods employed}

To test this hypothesis, female C57BL/6 mice (National Institutes of Aging) received three injections of $100 \mu \mathrm{g}$ of CpnCTL7 or VR1012 plasmid DNA as previously described [10]. Twelve days after the third dose, C57BL/6 mice, at 6 and 20 months of age, were infected by intranasal inoculation with $5.0 \times 10^{5}$ IFU of C. pneumoniae (AR39; ATCC, Rockville MD), in HBSS [7]. Uninfected mice received HBSS alone. Mice were euthanized 14 or 28 days after infection by $\mathrm{CO}_{2}$ asphyxiation. Lungs and hearts/ ascending aortae were removed, snap frozen in liquid nitrogen and stored at $-80^{\circ} \mathrm{C}$ until assay.

To test for the presence of Chlamydia in tissue samples, four-well chamber slides (Lab Tech, Naperville, Ill) were seeded with $1.4 \times 10^{5} \mathrm{HEp}-2$ cells/well and incubated overnight at $37^{\circ} \mathrm{C}$ in $5 \% \mathrm{CO}_{2}$. Serial 10 -fold dilutions of tissue homogenate prepared as described previously [6] were added to the wells. Negative control wells contained HEp-2 cells in media alone. The slides were centrifuged at 390xg for $30 \mathrm{~min}$ (Sorvall Legend RT, Kendro Laboratory Products, Asheville, NC). After $2 \mathrm{~h}$ at $37^{\circ} \mathrm{C}$, cycloheximide (Sigma Scientific, St. Louis, MO, final concentration $=2 \mu \mathrm{g}$ / $\mathrm{ml}$ ) was added and the chamber slides were incubated for an additional $72 \mathrm{~h}$ at $37^{\circ} \mathrm{C}$. Slides were washed with PBS, fixed with Cytofix/Cytoperm (BD Biosciences, San Diego, $\mathrm{CA}$ ) for $30 \mathrm{~min}$, and washed again in PBS. Slides were treated with a $1 \mathrm{X}$ Perm/Wash solution (BD Biosciences, San Diego, CA) for $15 \mathrm{~min}$ and stained with $0.2 \mu \mathrm{g}$ FITCconjugated Chlamydia trachomatis LPS-specific antibody (Catalog \#61-C75, Fitzgerald Industries Intl., Concord, MA) in PBS for $60 \mathrm{~min}$ at $37^{\circ} \mathrm{C}$. Slides were washed, counterstained with a 1:1,000 dilution of bisBenzamide $(1 \mu \mathrm{g} / \mathrm{mL}$, Sigma Scientific, St. Louis, MO) in PBS, and rinsed again. Slides were mounted in Gel/Mount (Biomeda Corp., Foster City, CA), cover-slipped and stored in the dark. Infected cells were counted at 600x magnification using a Nikon Eclipse E800 microscope. Titers were calculated as described previously [7].

One-way analysis of variance (ANOVA) tests were performed using SPSS.

\section{The CpnCTL7 vaccine provides protection against respiratory $C$. pneumoniae infection in both young and aged C57BL/6 mice}

At 14 days post-infection (p.i., Figure 1A), all (4/4) nonvaccinated young $\mathrm{C} 57 \mathrm{BL} / 6$ mice had evidence of $C$. pneumoniae respiratory infection (mean titer $=6.0 \times 10^{4}$ IFU/ml, range: $\left.1.0 \times 10^{4}-5.0 \times 10^{5} \mathrm{IFU} / \mathrm{ml}\right)$. In contrast, the CpnCTL7 vaccine protected against respiratory $C$. pneumoniae infection in all 5 infected young mice $(\mathrm{p}=0.001)$. Similarly, 3 of $4(75 \%)$ non-vaccinated aged mice had detectable $C$. pneumoniae in the lung; but none of the 4 aged, vaccinated mice had detectable $C$. pneumoniae titers at 14 days p.i. $(\mathrm{p}=0.012)$. These results suggest that the cytolytic $\mathrm{T}$ cell response induced by the CpnCTL7 vaccine was of sufficient magnitude in aged mice to provide at least temporary protection against $C$. pneumoniae infection.

None of the uninfected (1 young, non-vaccinated, 2 young, vaccinated, and 3 aged, vaccinated) control mice had detectable C. pneumoniae titers (data not shown).

At 28 days p.i., 12 out of 13 (92\%) young, nonvaccinated mice had $C$. pneumoniae lung titers (range: $\left.1.0 \times 10^{2}-5.0 \times 10^{3} \mathrm{IFU} / \mathrm{ml}\right)$. The geometric mean titer for non-vaccinated young mice $\left(5.4 \times 10^{2} \mathrm{IFU} / \mathrm{ml}\right)$ was approximately 100 -fold lower at 28 days p.i. than at 14 days p.i. $\left(6.0 \times 10^{4} \mathrm{IFU} / \mathrm{ml}\right)$, indicating that young C57BL/6 mice control respiratory C. pneumoniae infection to some degree without vaccination. Yet, clearance of the organism may be promoted by vaccination. At 28 days p.i., 9 of the 15 (60\%) young, vaccinated mice had no evidence of $C$. pneumoniae in the lung (Figure 1B), compared to only $8 \%$ (1 of 13 ) in the non-vaccinated group. The remaining 6 (40\%) young, vaccinated mice showed nom-

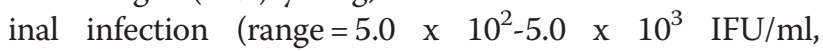
Figure 1B).

In contrast to that observed in young non-vaccinated mice, the infection established in aged mice following intranasal inoculation of $C$. pneumoniae appears to be progressive. The geometric mean titer from lungs of aged, unvaccinated mice at 28 days p.i. $\left(1.9 \times 10^{4} \mathrm{IFU} / \mathrm{ml}\right)$ was 10 -fold higher than that obtained at 14 days p.i. $\left(1.7 \times 10^{3}\right.$ IFU/ml). C. pneumoniae was detected in all (11/11) aged, non-vaccinated C57BL/6 mice at 28 days p.i. (Figure $1 \mathrm{~B}$ ). Still, the vaccine remains at least partially protective in aged mice; 5 of the 11 (45\%) aged, vaccinated mice were clear of respiratory C. pneumoniae infection at 28 days p.i. The remaining $55 \%$ of aged, vaccinated mice had lung titers that ranged from $1.0 \times 10^{3}$ to $2.0 \times 10^{4} \mathrm{IFU} / \mathrm{ml}$ (Figure 1B). The geometric mean for all aged, vaccinated mice was $5.4 \times 10^{2} \mathrm{IFU} / \mathrm{ml}$ which is 35 -fold lower than that of aged, non-vaccinated animals, but not statistically significant $(p=0.109)$. These results suggest that the CTL response elicited in both young and aged mice still protects against respiratory infection in at least a subset of each group. Our results, however, indicate that a reservoir of infection existed over the 28 day period in some vaccinated mice, regardless of age. It is possible that the cytolytic response or the cytokines (including IFN- $\gamma$ ) produced by the CTL, drove the course of infection into a persistent state in some animals, as has been described by others [11]. 


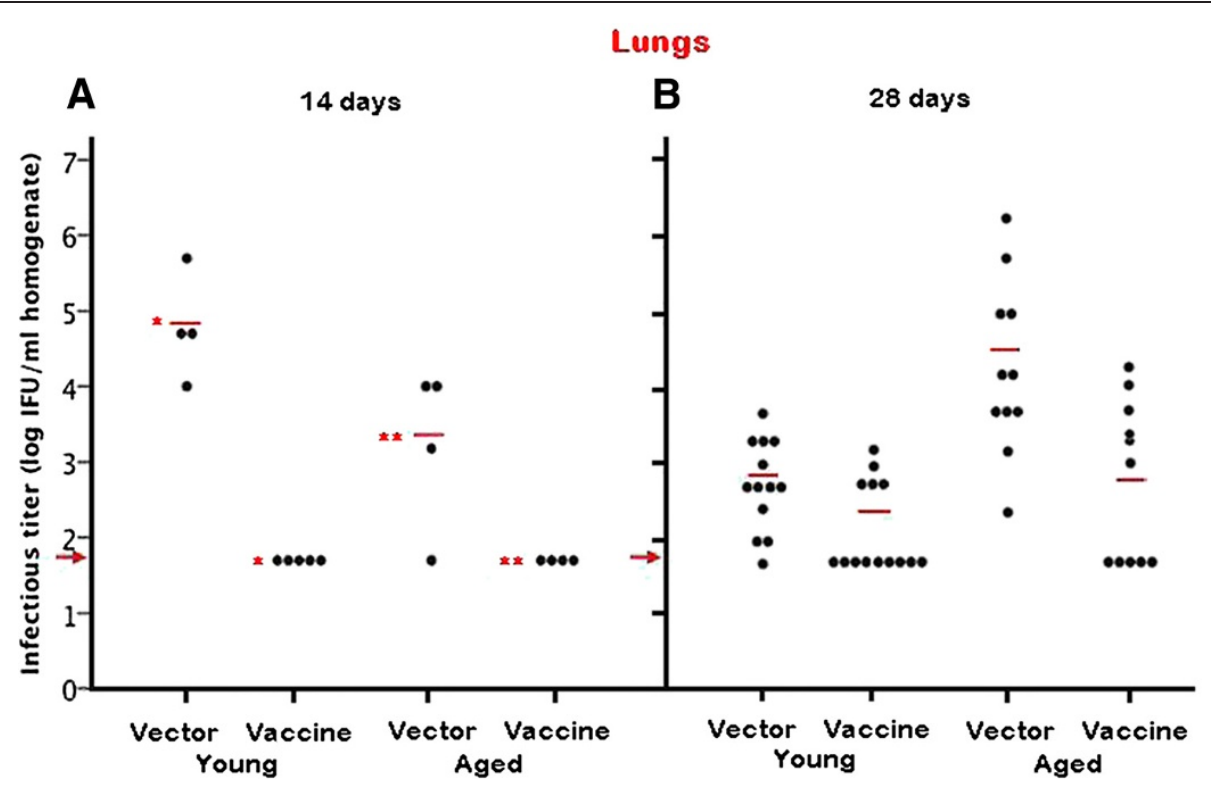

Figure 1 Recovery of $C$. pneumoniae from the lung 14 and 28 days after intranasal inoculation of $5 \times 10^{5}$ IFU 6-month-old (young) or 20-month-old (aged) C57BL/6 mice were immunized with $100 \mu \mathrm{g}$ of CpnCTL7 (vaccine) or VR1012 plasmid DNA (vector) and challenged intranasally with $5 \times 10^{5}$ IFU C. pneumoniae 12 days after completion of the immunization protocol. Mice were euthanized 14 days (A) or 28 days (B) after infection, the lungs were removed, and lysates prepared as described in Materials and Methods. Viable organisms were recovered and quantified by immunofluorescent staining using FITC-conjugated Chlamydia-specific antibody (Fitzgerald 61-C75). The groups of experimentally infected and uninfected age-matched control mice are listed on the X-axis and the number of inclusion forming units/ml of $10 \%$ weight/volume homogenate $\left(\log _{10}\right)$ is displayed on the Y-axis. Each dot represents the concentration (IFU/ml) of C. pneumoniae recovered from the organ homogenate of an individual mouse. The red bars indicate the geometric mean of all animals in each group ( $\left.\log _{10}\right)$ and the red arrow indicates the limit of $C$. pneumoniae in the detection system. The "***" symbols indicate a statistically significant difference $(p=0.025)$ between the geometric mean of respiratory titers of aged, vaccinated mice and aged mice receiving vector alone.

No detectable C. pneumoniae titers were found in any uninfected mice (3 young non-vaccinated, 3 young vaccinated, 2 aged non-vaccinated and 5 aged vaccinated mice, data not shown).

\section{Effect of age and vaccination status on spread of C. pneumoniae to the cardiovascular system}

Cardiovascular infection is a common sequella of respiratory C. pneumoniae infection in both C57BL/6 (Figure 2) and BALB/c mice [6]. While cardiovascular infection may be established without overt symptoms, infection may trigger a chronic immune and/or inflammatory response that would contribute to the development and/or progression of pathology [6]. Thus, protective vaccination that would limit or prevent the spread of C. pneumoniae to the cardiovascular system might be an effective strategy in preventing or delaying age-related cardiovascular pathologies.

Our results show that, by 14 days p.i., all (4/4) of the young, non-vaccinated mice showed signs of C. pneumoniae spread to the heart/ascending aorta (geometric mean $=1.0 \times 10^{4} \mathrm{IFU} / \mathrm{ml}$, range: $5.0 \times 10^{2}-5.0 \times 10^{7}$ IFU/ml, Figure 2A). In contrast, none $(0 / 4)$ of young vaccinated mice showed any signs of cardiovascular infection at 14 days p.i. (Figure 2A). Similarly, all 4 aged, non-vaccinated animals displayed signs of cardiovascular infection at 14 days p.i. (geometric mean $=3.9 \times 10^{4}$ IFU/ml, range: $1.0 \times 10^{3}-1.0 \times 10^{7} \mathrm{IFU} / \mathrm{ml}$, Figure $2 \mathrm{~A}$ ). Only 1 of the 4 (25\%) of the aged, vaccinated mice showed demonstrable cardiovascular infection $\left(2.5 \times 10^{3}\right.$ $\mathrm{IFU} / \mathrm{ml}$ ) at 14 days p.i. (Figure $2 \mathrm{~A}$ ). The geometric mean for the aged, non-vaccinated mice was 288-times higher than that in aged, vaccinated mice $(\mathrm{p}=0.025)$.

At 28 days p.i., 11 of the 13 (85\%) young nonvaccinated mice had evidence of $C$. pneumoniae infection in the heart/ascending aorta (range: $5.0 \times 10^{2}-5.0 \mathrm{x}$ $10^{6} \mathrm{IFU} / \mathrm{ml}$, Figure 2B). Extra-respiratory spread was drastically reduced by vaccination in young mice. Only $40 \%$ (6 out of 15 ) of young vaccinated mice showed detectable infection in the heart/ascending aorta (range: $1.0 \times 10^{3}-1.0 \times 10^{5} \mathrm{IFU} / \mathrm{ml}$, Figure 2B). The geometric mean C. pneumoniae titer for the young, non-vaccinated animals $\left(5.9 \times 10^{3} \mathrm{IFU} / \mathrm{ml}\right)$ was 17 -fold higher than that of young, vaccinated animals $\left(3.4 \times 10^{2} \mathrm{IFU} / \mathrm{ml}\right)$, a difference that was not statistically significant.

All (11 out of 11) of the aged, non-vaccinated animals displayed signs of infection in the heart/ascending aorta (range: $5.0 \times 10^{2}-1.0 \times 10^{7} \mathrm{IFU} / \mathrm{ml}$, geometric mean $=1.0$ $\mathrm{x} 10^{5} \mathrm{IFU} / \mathrm{ml}$, Figure $2 \mathrm{~B}$ ) at 28 days p.i. The vaccine, 


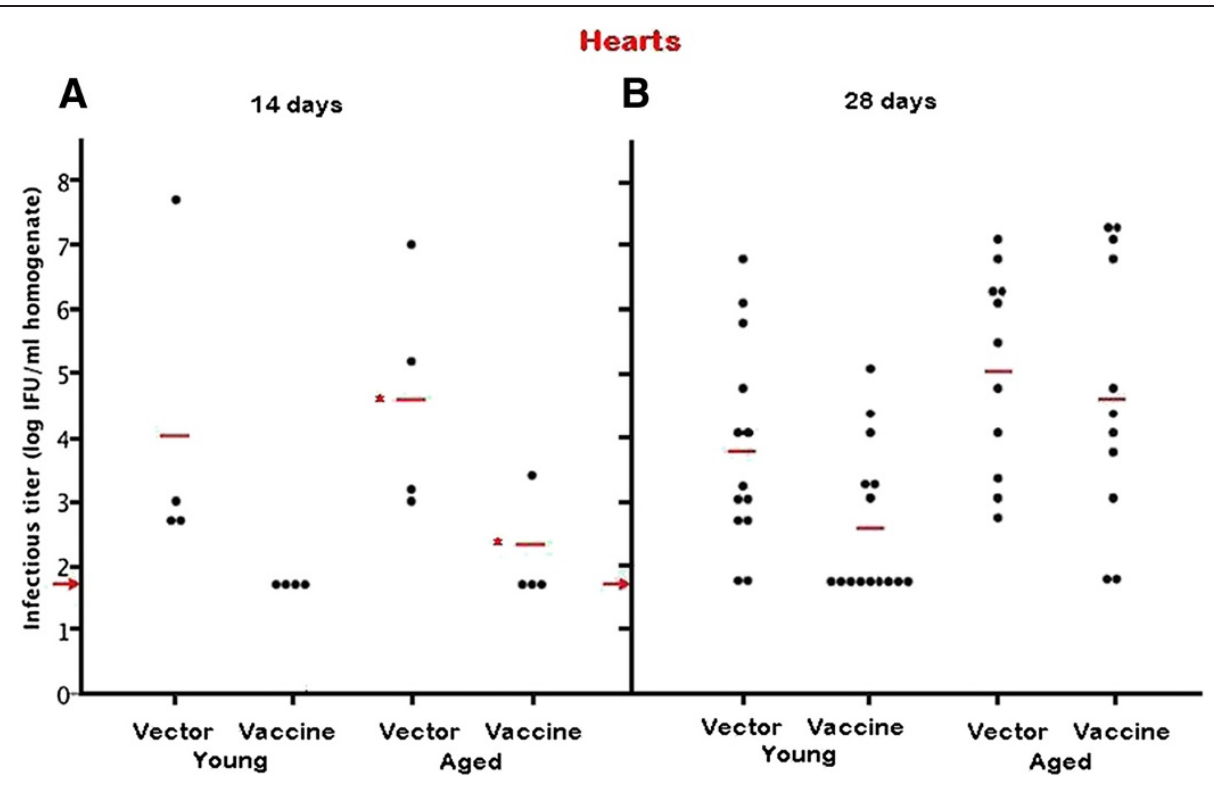

Figure 2 Recovery of $C$. pneumoniae from the heart 14 and 28 days after intranasal inoculation of $5 \times 10^{5}$ IFU 6-month-old (young) or 20-month-old (aged) C57BL/6 mice were immunized with $100 \mu \mathrm{g}$ of CpnCTL7 (vaccine) or VR1012 plasmid DNA (vector) and challenged intranasally with $5 \times 10^{5}$ IFU C. pneumoniae 12 days after completion of the immunization protocol. Mice were euthanized 14 days $(\mathbf{A})$ or 28 days (B) after infection, the hears/ascending aortae were removed, and lysates prepared as described in Materials and Methods. Viable organisms were recovered and quantified by immunofluorescent staining using FITC-conjugated Chlamydia-specific antibody (Fitzgerald 61-C75). The groups of experimentally infected and uninfected age-matched control mice are listed on the $\mathrm{X}$-axis and the number of inclusion forming units $/ \mathrm{ml}$ of $10 \%$ weight/volume homogenate $\left(\log _{10}\right)$ is displayed on the $Y$-axis. Each dot represents the concentration (IFU/ml) of C. pneumoniae recovered from the organ homogenate of an individual mouse. The red bars indicate the geometric mean of all animals in each group ( $\left.\log _{10}\right)$ and the red arrow indicates the limit of $C$. pneumoniae in the detection system. The "**" symbol indicates a statistically significant difference $(p=0.001)$ between the geometric mean of respiratory titers of young, vaccinated mice and young mice receiving vector alone. The "***" symbols indicate a statistically significant difference $(p=0.012)$ between the geometric mean of respiratory titers of aged, vaccinated mice and aged mice receiving vector alone.

however, did not protect against extra-respiratory spread in aged animals; 9 of 11 (82\%) of aged, vaccinated mice had detectable infections (range: $1.0 \times 10^{3}$ to $1.5 \times 10^{7}$ IFU/ml, Figure 2B) with a geometric mean of $4.5 \times 10^{4}$ $\mathrm{IFU} / \mathrm{ml}$. These results indicate that while vaccination delays or prevents spread to the cardiovascular system in young mice, this strategy was not protective in aged mice; spread to the cardiovascular system was observed in $82 \%$ of aged, vaccinated mice by 28 days p.i.

These data suggest that, despite reports of intrinsic and extrinsic age-associated defects in CTL $[12,13]$ including alterations in the diversity repertoire [reviewed in [14]], CD8+ CTL precursor, vaccine epitope-specific, cells must be induced in sufficient frequencies in aged mice to mount a protective response in the lung that closely parallels that seen in their young counterparts.

However, the CD8+ CTL response generated by the vaccine is not sufficient to provide long-term cardiovascular protection, especially in aged animals. One possibility is that extrinsic factors that could decrease the CTL response generated to the vaccine in aged mice may vary by site. Thus, the CTL response elicited by the vaccine, while remaining effective in the lungs, may have been inhibited in the cardiovascular system of aged mice via $\mathrm{CD} 4^{+} \mathrm{CD} 25$ ${ }^{+} \mathrm{FoxP}^{+}$regulatory cells, which increase in number during aging [15]. Another possible explanation of these findings is that the immune mechanisms that control respiratory C. pneumoniae burden differ from those that regulate extra-respiratory spread or the establishment of systemic infection. In this scenario, the CTL response generated by the vaccine may not prevent or may even promote spread to the cardiovascular system [11]. Finally, it is possible that non-immune age-related processes, such as atherosclerosis, contribute to the higher burden of cardiovascular infection and/or relative lack of vaccine efficacy in the aged. Wild type C57BL/6 mice fed normal low-fat laboratory chow, even at advanced age, do not show significant atherosclerotic changes within the aorta [16]. Still, other agerelated changes inherent to or affecting the vascular endothelium may promote infection of these cells and thus, contribute to the burden of C. pneumoniae in the hearts/ ascending aortae of aged mice.

\section{Abbreviations}

CTL: Cytotoxic T lymphocyte; IFU: Infection forming units; HBSS: Hanks buffered salt solution; PBS: Phosphate buffered saline. 


\section{Competing interests}

The authors declare that they have no competing interests.

\section{Acknowledgements}

The authors wish to thank Alice Lee and Denah Appelt for helpful discussions and advice and Jason Kilgore for his guidance on the statistical analyses. This work was supported by grant AG18320 from the National Institute of Aging (KFD), grant HL70641 from the National Institutes of Health (BW) and funding from the Osteopathic Heritage Foundation endowed Center for Chronic Disorders of Aging at PCOM (BB and KFD).

\section{Author details}

'Department of Biology, Washington and Jefferson College, Washington, PA 15301, USA. ${ }^{2}$ Department of Pathology, Microbiology, Immunology, and Forensic Medicine and the Center for Chronic Disorders of Aging, Philadelphia College of Osteopathic Medicine, Philadelphia, PA 19131, USA. ${ }^{3}$ Department of Microbiology and Immunology, Center for Pulmonary and Infectious Disease Control, University of Texas Health Center, Tyler, Texas 75708, USA. ${ }^{4}$ Department of Pathology, Microbiology, and Immunology, the Philadelphia College of Osteopathic Medicine, 4170 City Avenue, Philadelphia, PA 19131, USA. ${ }^{5}$ Current address: Intercell AG, Campus Vienna Biocenter 3, Vienna 1030, Austria.

\section{Authors' contributions}

TE performed the immunofluorescence assays described herein, participated in the statistical analyses and critical analysis of the data, and wrote the first drafts of the manuscript. SB and AS performed the immunofluoresence assays. CSL and BB contributed significantly to the experimental design, performed the animal work, and provided critical analyses of the data, interpretations, and manuscript. DS prepared the vaccine and vector preparations for the study. BW, provided the vaccine and vector stocks for the study, contributed significantly to the experimental design, and provided critical analyses of the data, interpretations, and manuscript. KLF-D,

(corresponding author) is the Principal Investigator in the laboratory and, as such, was centrally involved in all aspects of the work represented in this manuscript. All authors read and approved the final manuscript.

Received: 1 November 2011 Accepted: 17 May 2012

Published: 17 May 2012

\section{References}

1. Blasi F, Tarsia P, Aliberti S, Cosentini R, Allegra L: Chlamydia pneumoniae and Mycoplasma pneumoniae. Sem in Respiratory Critical Care Med 2005 26:617-624.

2. Campbell LA, Kuo CC: Chlamydia pneumoniae-an infectious risk factor for atherosclerosis. Nature Rev Microbiol 2004, 2:23-32.

3. Mosorin M, Surcel HM, Laurila A, Lehtinen M, Karttunen R, Juvonen J, Paavonen J, Morrison RP, Saikku P, Juvonen T: Detection of Chlamydia pneumoniae-reactive T lympocytes in human atherosclerosis plaques of carotid artery. Arterioscler Thromb Vasc Biol 2000, 20:1061-1067.

4. Gnarpe J, Gnarpe H, Gause-Nilsson I, Lundorg P, Steen B: Seroprevalence of antibodies to Chlamydia pneumoniae in elderly people: a two-decade longitudinal and cohort study. Scand J Infect Dis 2000, 32:177-179.

5. O'Neill C, Murray L, Ong GM, O'Reilly DP, Evans AE, Bamford KB: Epidemiology of Chlamydia pneumoniae infection in a randomly selected population in a developed country. Epidemiol Infect 1999, 122:111-116.

6. Chen WH, Kozlovsky BF, Effros RB, Grubeck-Loebenstein B, Edelman R, Sztein MB: Vaccination in the elderly: an immunologic perspective. Trends Immunol 2009, 30:351-359.

7. Little CS, Bowe A, Lin R, Litsky J, Fogel RM, Balin BJ, Fresa-Dillon KL: Age alterations in extent and severity of experimental intranasal infection with Chlamydophila pneumoniae in BALB/c mice. Infect Immun 2005, 73:1723-1734

8. Vuola JM, Puurula V, Anttila M, Makela PH, Rautonen N: Acquired immunity to Chlamydia pneumoniae is dependent on gamma interferon in two mouse strains that initially differ in this respect after primary challenge. Infect Immun 2000, 68:960-964.

9. Rottenberg ME, Gigliotti Rothfuchs AC, Gigliotti D, Svanholm C, Bandholtz L, Wigzell $\mathrm{H}$ : Role of innate and adaptive immunity in the outcome of primary infection with Chlamydia pneumoniae, as analyzed in genetically modified mice. J Immunol 1999, 162:2829-2836.

10. Pinchuk I, Starcher BC, Livingston B, Tvninnereim A, Wu S, Appella E, Sidney J, Sette A, Wizel B: A CD8+ T Cell heptaepitope minigene vaccine induces protective immunity against Chlamydia pneumoniae. J Immunol 2005, 174:5729-5739.

11. Pantoja $L G$, Miller RD, Ramirez JA, Molestina RE, Summersgill JT: Characterization of Chlamydia pneumoniae persistence in HEp-2 cells treated with gamma interferon. Infect Immun 2001, 69:7927-7932.

12. Effros RB, Cai Z, Linton PJ: CD8 T cells and aging. Crit Rev Immunol 2003, 23:45-64.

13. lancu EM, Speiser DE, Rufer $N$ : Assessing ageing of individual $T$ lymphocytes: Mission impossible. Mech Ageing Devel 2008, 129:67-78.

14. Yewdell JW, Haeryfar SM: Understanding presentation of viral antigens to CD8+ T cells in vivo: The key to rational vaccine design. Ann Rev Immunol 2005, 23:651-682.

15. Nishioka T, Shimuzu J, lida R, Yamazaki S, Sagaguchi S: CD4 + CD25 + FoxP3+ T cells in aged mice. J Immunol 2005, 176:6586-6593.

16. Tennett GA, Hutchinson WL, Kahan MC, Hirschfield GM, Gallimore JR, Lewin J, Sabin CA, Dhillon AP, Pepys MB: Transgenic human CRP is not pro-atherogenic, pro-atherothrombotic or pro-inflammatory in apoE-I- mice. Atherosclerosis 2008, 196:248-255.

doi:10.1186/1742-4933-9-11

Cite this article as: Eddens et al: Effect of age and vaccination on extent and spread of Chlamydia pneumoniae infection in C57BL/6 mice. Immunity \& Ageing 2012 9:11.

\section{Submit your next manuscript to BioMed Central and take full advantage of:}

- Convenient online submission

- Thorough peer review

- No space constraints or color figure charges

- Immediate publication on acceptance

- Inclusion in PubMed, CAS, Scopus and Google Scholar

- Research which is freely available for redistribution

Submit your manuscript at www.biomedcentral.com/submit
C BioMed Central 